\title{
Ingestion of Caustics by Children in Brazzaville (CONGO)
}

\author{
Lucie Charlotte Atipo-Ibara Ikobo Ollandzobo 1,2*, Clausina Ahoui-Apendi1,3, \\ Jile Florient Mimiesse-Monamou, 1,3, Jean Robert Mabiala Babela ${ }^{1,2}$, Deby-Gassaye ${ }^{1,3}$, \\ Blaise Irénée Atipo Ibara1,3, Jean-Rosaire Ibara ${ }^{1,3}$ \\ ${ }^{1}$ Faculty of Health Sciences, Marien Ngouabi University, Brazzaville, Congo \\ ${ }^{2}$ Infant Pediatric Service, University Hospital of Brazzaville, Brazzaville, Congo \\ ${ }^{3}$ Gastroenterology and Internal Medicine Service, University Hospital of Brazzaville, Brazzaville, Congo \\ Email: lucieatipo@hotmail.fr
}

How to cite this paper: Ollandzobo, L.C.I.A.I., Ahoui-Apendi, C., MimiesseMonamou, J.F., Babela, J.R.M., Deby-Gassaye, Ibara, B.I.A. and Ibara, J.-R. (2018) Ingestion of Caustics by Children in Brazzaville (CONGO). Open Journal of Pediatrics, 8 , 283-291.

https://doi.org/10.4236/ojped.2018.83029

Received: September 5, 2018

Accepted: September 27, 2018

Published: September 30, 2018

Copyright $\odot 2018$ by authors and Scientific Research Publishing Inc. This work is licensed under the Creative Commons Attribution International License (CC BY 4.0).

http://creativecommons.org/licenses/by/4.0/

\begin{abstract}
Ingestion of caustics by children is serious because of the increase in their frequency and the difficulties due to their management. Objective: To improve the management of caustic lesions in Pediatric Department at the University Hospital of Brazzaville. Patients and Methods: Prospective study was conducted from January 2014 to December 2015 in the Pediatric Departments of the UHB and centers of digestive endoscopy in Brazzaville. All children who ingested a caustic product and hospitalized were included after obtaining parental's consent. The studied parameters were: Age, sex, nature and quantity of the caustic, the family's attitude, clinical signs, endoscopic results according to Zagar's classification, therapeutic modalities and evolution. Results: 8292 children were hospitalized and 68 because of the ingestion of caustic, a frequency of $0.8 \%$. The average age was 23.6 months [ 2 months 16 years]. The male sex was predominant (57.4\%). Ingestion was accidental in $88.2 \%$ and voluntary in $11.8 \%$. Factors favoring ingestion were storage methods $(81.5 \%)$ and parental's inattention or negligence $(10.8 \%)$. Bleach was the most incriminated caustic (54.4\%) followed by caustic soda $(29.4 \%)$. The estimated quantity ingested was assumed to be minimal in $61.7 \%$. Unsuitable acts were practiced by the family before the medical consultation in $66.1 \%$. The dominant symptoms were digestive (47\%) and neurological (25\%). The average time to perform endoscopy was 48 hours in $88.2 \%$. Endoscopy revealed lesions in $51.7 \%$, the different stages were I ( 12 cases), II (16 cases) and III ( 3 cases). The mains factors of gravity were inappropriate gestures (85\%) and the non-respect of the fasting (9\%). Proton pump inhibitors were used in $50 \%$. The evolution was favorable for in $73.5 \%$. Conclusion: Ingestion of caustics by children is most often accidental favored by the inadequate pack-
\end{abstract}


aging and storage. Prevention is about educating people in order to reduce

their frequency.

\section{Keywords}

Caustic Lesions, Child, Brazzaville

\section{Introduction}

Ingestions of caustics in children are worrying because of the increase in their frequency and the difficulties inherent in their management. They frequently occur accidentally in children in $95 \%$ of cases with male predominance, between 1 and 5 years [1] [2]. It is a real-life accident whose life is dramatic, responsible for the caustic lesions (burns caused by the contact of the digestive mucosa with the ingested caustic product) of the digestive tract [3].

Ingestions of caustics represent a public health problem because they affect all continents. The global incidence, according to WHO in 2004, was 110 cases per 1000 people per year, of which $30 \%$ were children [2] [4] [5]. In developed countries, the incidence has decreased considerably due to the impact of prevention measures in the populations [6] [7] [8]. In developing countries, particularly in sub-Saharan Africa, prevalence is increasing. The rapid urbanization since the 1970s, the consumption of herbal teas of traditional preparations and the explosion of suicide attempts among adolescents are the main factors [5] [6] [9].

Caustic burns are benign in $75 \%$ of cases, but sometimes they are severe, life-threatening and functional, with an overall mortality of $10 \%$ and $10 \%-40 \%$ of sequelae [3] [4]. This is a medico-surgical emergency requiring rapid multidisciplinary management in a specialized environment with a digestive endoscopy unit [1] [2] [5].

The severity of the lesions is assessed by upper gastrointestinal endoscopy (UGE), the only standard examination to establish the diagnosis, prognosis and conditioning treatment [5] [6]. The severity of these caustic burns depends on the nature and quantity of the caustic involved [2] [3] [5]. But also because the potential evolution can be towards stenosis or cancer [2] [5].

In the Congo, according to hospital studies in children, caustic ingestions account for $10.6 \%$ of acute poisoning [10] and $37.8 \%$ of UGE indications [11]. In order to improve the management of the causative pathology of the child at the Brazzaville University Hospital, we conducted this study which aims to describe the clinical and endoscopic aspects of the children who have ingested the caustics, to determine the factors of gravity, and describe therapeutic modalities and evolutionary aspects.

\section{Materials and Methods}

This was a prospective, descriptive study carried out during the period from 
January 1, 2014 to December 31, 2015, that is 2 years, in the pediatric departments of the Brazzaville University Hospital Center and in the private health centers. digestive endoscopy; having a suitable endoscopy equipment adapted to the child where all the upper gastrointestinal endoscopy were performed.

The study population was represented by all children hospitalized in the pediatric ward during the study period. Children aged 1 month to 16 years, hospitalized for caustic ingestion and those whose records were exploitable (i.e., including at least one medical observation, a temperature and treatment sheet, a report of upper digestive endoscopy) were included after obtaining the informed consent of the parents or legal guardian. High digestive endoscopies were performed with Olympus branded devices. Olympus ${ }^{\circledR}$ GIF V2 and GIF Q 145 type endoscopes suitable for older children. They are 1.20 meters long and 3.5 millimeters in diameter for the first and 3.8 for the second. The Olympus ${ }^{\circledR}$ GIF N180 type endoscope, exclusively pediatric, also measures 1.20 meters for 2 millimeters in diameter. The examination was performed by gastroenterologists without general anesthesia, sedation with diazepam 3\% drop was sometimes considered in agitated infants and a local oro-pharyngeal anesthesia Lidocaine viscous gel was performed in older children, able to cooperate. The severity of the lesions was assessed according to the endoscopic classification proposed by Zargar [3] which defines four stages of the caustic lesions of increasing gravity. The opacification with a water-soluble product allows a good analysis of the stenoses. It specifies the number, the seat, the extent and the evolution of these.

The studied parameters were: the nature, the name and the quantity of the ingested product, the attitude of the entourage of the addict, the clinical signs, the type of lesions to appreciate according to the classification of Zargar, the factors of gravity, the therapeutic and evolutionary modalities.

The data was collected on a pre-established survey form; from the questioning of the parents and the records of hospitalization. The sampling mode was consecutive. Data entry and analysis was done with Epi Info version 3. 3. 2 and $\mathrm{Mi}$ cro Soft Word 2013 software. Qualitative variables were expressed as a percentage and quantitative variables as average and/or standard deviation. The calculation of Odd-ratio and their confidence interval allowed the assessment of the risk of occurrence of lesions after ingestion of the caustic. Pearson's chi-square test allowed us to assess the statistical significance of perceived differences with a threshold of significance $<0.05$.

\section{Results}

Of 8292 children hospitalized during the study period, 68 had ingested a caustic, a hospital frequency of $0.8 \%$. Their average age was 23.6 months (range 2 months and 16 years). Male children accounted for $57.4 \%$ of cases $(n=39)$ and female children for $42.6 \%$ of cases $(n=29)$, representing a sex-ratio of 1.3 . Ingestion was accidental in $88.2 \%(n=60)$ and voluntary in $11.8 \%(n=8)$. Factors favoring ingestion was frequently the caustic storage method $81.5 \%$ case $(\mathrm{n}=$ 
$53)$, in bottles of mineral water $54.4 \%$ case $(n=37)$, followed by inattention or neglect guardians $10.8 \%$ case $(n=7)$. Bleach was the most incriminated caustic 37 cases $(54.4 \%)$, followed by caustic soda 20 cases $(29.4 \%)$, sulfuric acid 7 cases $(10.3 \%)$ and 3 cases $(4.4 \%)$ of herbal tea. The estimated quantity ingested is recorded in Table 1 . The inappropriate attitude of the entourage before the medical consultation was observed in 45 children (66.1\%). This was the administration of water coupled with an induction of vomiting $62.3 \%(n=28)$, the administration of water and milk 20\% ( $\mathrm{n}=9)$, then the administration of other products coupled with induced vomiting $17.7 \%(n=5)$. The average completion time for HRE was 48 hours (24-hour and 72-hour extremes). According to this delay, the patients were divided into 3 groups: 24 cases (40\%) before 24 hours, 21 cases (35\%) between 24 and 48 hours and 15 cases (25\%) beyond 72 hours. 58 children (85.2\%) had clinical symptoms, dominated in descending order by digestive signs 32 cases (47\%) (Table 2), neurological signs 17 cases (25\%) and skin burns 9 cases (13\%), 2\%). Table 3 distributes the children according to endoscopic results according to Zargar's classification. The various endoscopic lesions objectified according to the seat are shown in Table 4. The maladaptive attitude was the main causative factor of caustic burns 45 cases (85\%), assisted by the non-compliance of the 5 cas diet (9\%), then the massive ingestion 3 cases $(6 \%)$. Table 5 shows the influence of the amount of ingested caustic on the risk of occurrence of oeso-gastro-duodenal burns. Children (98.5\%) received water intake. In the absence of oeso-gastro-duodenal lesions or in the presence of superficial lesions (stage I), oral feeding was resumed immediately in 29 children and no

Table 1. Distribution of children by quantity of ingested caustic.

\begin{tabular}{ccc}
\hline Quantity & $\mathbf{n}$ & $\%$ \\
\hline Minimal $(<15 \mathrm{ml})$ & 42 & 61.7 \\
Moderate $(>15-30 \mathrm{ml})$ & 9 & 13.2 \\
Important $(>30-40 \mathrm{ml})$ & 5 & 7.3 \\
Unspecified & 12 & 17.8 \\
Total & $\mathbf{6 8}$ & $\mathbf{1 0 0 \%}$ \\
\hline
\end{tabular}

Table 2. Distribution of digestive symptoms.

\begin{tabular}{ccc}
\hline Symptômes & n & \% \\
\hline Oral enanthemum & 25 & 28.1 \\
Hypersialorrhea & 11 & 15.6 \\
Lingual erosions/glossitis & 9 & 12.5 \\
Oropharyngeal Ulcérations & 9 & 12.5 \\
Vomiting & 8 & 9.4 \\
Breath having a bleach smell & 4 & 6.3 \\
Abdominal pain & 4 & 6.3 \\
Odynophagia & 3 & 3.1 \\
Hématemisis & 3 & 3.1 \\
Melena & 1 & $\mathbf{1 0 0 \%}$ \\
TOTAL & 32 & \\
\hline
\end{tabular}


Table 3. Distribution of children according to the results of upper digestive endoscopy.

\begin{tabular}{ccc}
\hline Results of the HDE & $\mathbf{n}$ & $\%$ \\
\hline normal Examination & 29 & 48.3 \\
Stage I & 12 & 20 \\
Stage II & 16 & 26.7 \\
Stage III & 3 & 5 \\
Total & 60 & $100 \%$ \\
\hline
\end{tabular}

Table 4. Different endoscopic lesions according to the seat.

\begin{tabular}{cccc}
\hline Lesion & Seat & $\mathbf{n}$ & $\%$ \\
\hline Inflammation congestion or œedema & Esophagus & 11 & 35.5 \\
Isolated superficial ulcerations & Esophagus & 14 & 45.1 \\
Circumferential ulcerations & Gastroesophageal cardiovascular & 2 & 6.5 \\
Sténosis & tuberosity & 3 & 9.7 \\
Mallory Weiss Syndrome & Esophagus/stomach & 1 & 3 \\
& Cardia & & \\
Total & & 31 & $100 \%$ \\
\hline
\end{tabular}

Table 5. Influence of the amount ingested on the risk of lesions occurring.

\begin{tabular}{ccccc}
\hline Ingested quantity & Present lesions & Absent lesions & OR [IC] & $P$ \\
\hline Minimal & 12 & 29 & $0.03[0.01-0.3]$ & 0.001 \\
Moderate & 8 & 1 & $12.9[1.6-103.3]$ & 0.01 \\
Important & 5 & 0 & $7.1[2.5-20.1]$ & 0.01 \\
\hline
\end{tabular}

treatment was prescribed. 30 children had intermediate (stage II) and/or deep (stage III) burns and received PPI proton pump inhibitors. Antibiotic therapy was initiated for approximately two weeks when the lesions were extensive and circular. Surgery was considered in 3 patients. The first patient underwent oesophagoplasty in France, the 2nd underwent lower gastrectomy with gastroduodenal anastomosis in Morocco, and the third was lost to surgery without surgery. 2 teenagers had benefited from psychotherapy. The evolution was favorable for 50 children (73.5\%). However, it was unknown in 14 children (20.6\%). We observed complications in 5 cases; this was a case of Mallory Weiss syndrome, a case of worsening of stage IIb to stage III lesions, then staged esophageal stenosis, a case of extensive oesophageal stenosis, a case of stenosis gastric and a case of death by gastrointestinal bleeding.

\section{Discussion}

The authors report the results of a study conducted in hospitalized children for caustic ingestion at Brazzaville University Hospital Center. The deadline was two years, and we noted some limitations in carrying out our study. In fact, Brazzaville University Hospital Center does not have a pediatric gastroenterology service, so all HRE were performed in private digestive centers; which required the movement of patients out of the hospital for this examination. Depending on 
their clinical condition, some patients could not benefit from HRE. The study concerned only children hospitalized for caustic ingestion, which is a bias in the evaluation of frequency in the general population. This is therefore a hospital frequency.

Young children are at risk of caustic poisoning, those collected in our study had a mean age of 23.6 months and a sex ratio of 1.3. Indeed, this dramatic accident is usually accidental in children with a high frequency peak between 1 and 5 years and a male predominance. The epidemiology in our series joins the data of the literature [4] [12] [13]. Household cleaning products are the leading cause of non-drug poisoning in children under 5 years of age [14] [15]. According to the ingested caustic, our study showed that oxidants (bleach) are the most incriminated. The predominance of bleach is due to its free and unconditioned sale, and storage in containers for food, which can be confusing and especially its domestic use for household maintenance. Our results corroborate those of many studies [2] [4] [5] [8].

The amount of caustic ingested in our series was minimal. This fact has also been observed by other authors [2] [4] [5] [16], this partly because of the pungent nature of its corrosive substances, which in contact with the oral and cutaneous mucosa, obliges the child to stop drinking and secondly by the reflex closure of the oesophageal sphincters in case of intoxication. Many authors [7] [11] [16] report that certain behaviors in case of ingestion of a caustic are dangerous and all are formally contraindicated, such as; induced vomiting, administration of water, milk or other antidote and gastric lavage practiced by those around the addict. In our work, the attitude of the entourage consisted in the administration of water coupled with the induction of vomiting in 1st intention before the medical consultation. This suggests that these practices reflect the beliefs and traditions of populations for antidote purposes.

Concerning the caustic pathology, the children can be asymptomatic in half of the cases [2] [3] [12] [15]. Vomiting and thoracoabdominal pain are the most common symptoms. Dysphagia is a fairly common reason for delayed consultation after ingestion of a neglected caustic. Hematemesis and respiratory distress are rare; their presence always testifies to the existence of severe gastroesophageal lesions. In our series half of the children showed no symptoms. In the rest of the children the examination had found predominantly cases of oral enanthemum; erosions and/or pharyngeal ulcerations and vomiting. Abdominal pain, a symptom uncorrelated to the severity of endoscopic lesions, is poorly observed in our work because there is a bias of appreciation in infants who can not express themselves. The vomiting frequently observed is linked to emetic maneuvers carried out by the entourage. Hematemesis has been rarely observed. These results are close to those of Lamireau et al. [2] in France and Roïda et al. [16] in Marrackech (Morocco) where half of the patients remained asymptomatic. The first author noted a predominance of vomiting, sternal and abdominal pain. The second found as main symptoms of vomiting and dysphagia. 
Endoscopy is indicated systematically in any child who has ingested a corrosive substance even in the absence of clinical symptoms [1] [8] [9]. The average time to complete this examination was $48 \mathrm{~h}$. For the majority of patients this examination was performed before the 24th and 48th hours. This result is superimposable to those of Bobin [12] in France and Roïda [16] which found the same delay. The realization of emergency endoscopy in the first 24 hours is essential, on the one hand, to eliminate a possible caustic burn and avoid unnecessary hospitalization. On the other hand, on the contrary, to assert an oeso-gastric lesion, to take stock of it, and to guide its management [12]. EDH showed lesions in the majority of cases, lesions were largely in stage 2 of Zargar and the oesophageal site was predominant. Aloulou et al. [7] in Tunisia described similar lesions; however, in their series oeso-cardiotuberotic localization was preponderant. The influence of the amount of ingested caustic on the risk of occurrence of the endoscopic lesions observed is evident in this work and corroborates the data of the literature [2] [12]. But this aspect can not be commented on here because of the small size of our sample; However, we did not find any relationship between the clinical signs and the type of lesions. The cases of stenosis observed are compatible with data from the literature [2] [12] [16]. The attitude of those around the addict and the non-respect of the diet incriminated in this work as factors of gravity of the caustic burns, would be favored by the cultural level of the parents and the beliefs or even customs of the populations. These factors have already been described in other studies [5] [13], but they are not yet the subject of consensus. Ingestion of a massive amount of caustic is a potential gravitational factor; but weakly found in this work due to reduced sampling.

In order to ensure compliance with fasting before performing the endoscopy, all children received water intake in the absence of solutes for parenteral nutrition. Half of the children with stage II and III lesions also received antibiotics and proton pump inhibitors (PPIs). The small number of psychologists in our institution, would be one of the reasons why almost all patients and guardians could not benefit from psychological support.

The evolution in our series has been favorable in most cases. Complications were observed, mainly oesophageal and gastric stenosis and one case of Mallory Weiss syndrome following induced vomiting. We recorded a death by digestive haemorrhage before the haemostatic surgical procedure. These evolutionary modalities are comparable to the French [2] [5] and Moroccan [16] data, where cases of stenosis have also been described. The unknown evolution in 14 children is attributable to early exits and against medical advice.

\section{Conclusion}

The caustic lesions are most often accidental, favored by the way in which caustic products are packaged in flasks of mineral water and stored in inappropriate places. The clinical and endoscopic signs are a function of the caustic and the 
quantity ingested.

\section{Conflicts of Interest}

The authors declare no conflicts of interest regarding the publication of this paper.

\section{References}

[1] Ibara, J.R., Mbemba, M.I., Okouo, M., Atipo-Ibara, B.I., Ngoma-Mambouana, Ph., Deby, G., et al. (1997) Caustic Lesions of the Upper Digestive Tract of the Adult. Etiological and Endoscopic Aspects about 104 Cases. Annal of Gastroenterology and Hepatology, 33, 136-139.

[2] Lamireau, T., Lanas, B.L., Deprez, C., Hammar, E.I., Vergnes, P., Demarquez, J.L., et al. (1997) Severity of the Ingestion of Caustic Products. Archives de Pédiatrie, 4, 529-534. https://doi.org/10.1016/S0929-693X(97)87571-9

[3] Celerier, M. and Gayet, B. (1965) Burns by Ingestion of Caustic. In: The Traumas of the Esophagus, Aenette-Blackwell, Paris, 9-64.

[4] Aidan, K., Cattan, P. and Celerier, M. (2000) Caustic Burns of the Upper Digestive Tract. In: Rambaud, J.C., Ed., Treaty of Gastroenterology, Flammarion Medicine-Sciences, Paris, 253-257.

[5] Mourey, F., Martin, L. and Jacob, J. (1996) Caustic Burns of the Esophagus. Anesthesia Service - Surgical Resuscitation Saint-Louis Hospital 751 Paris Cedex: 1996 Update Conferences, 595-606.

[6] Sylla, M., Coulibaly, Y., Dickofi Kourouma, N., Togo, B. and Keita, M.M. (2006) Accidental Acute Poisoning in Pediatric Children at Gabriel TOURE Hospital. Mali Medical, 21, 53-3.

[7] Aloulou, H., Maaloul, I., Yaich, S., Kammoun, F. and Hachida, M. (2011) Digestive Fibroscopy in Children: Indications and Results. Experience of a General Pediatric Service. Journal of Pediatrics and Childcare, 24, 111-117.

[8] Lachaux, A., Mas, E., Breton, A., Barange, K., Heresbach, D. and Molard, B.R. (2011) Consensus in Digestive Endoscopy: Management of Caustic Esophagitis. Acta Endoscopica, 4, 303-308. https://doi.org/10.1007/s10190-011-0191-7

[9] Ibara, J.R., Atipo-Ibara, B.I., Boloko, Ch., Abena, A.A. and Itoua-Ngaporo, A. (2007) Corrosive Lesions of the Digestive Tract Secondary to the Use of Traditional Preparations. Study of 15 Congolese Cases. Phytotherapy, 5, 177-181.

[10] EKouya-Bowassa, G., Oko, G., Okoko, A.R. and Middle, G.M. (2008) Acute Intoxication in Children in Brazzaville. Revue du CAMES, 6, 85-87.

[11] Mbika Cardorelle, A., Missambou Mandilou, S. and Okoko, A. (2011) Upper Gastrointestinal Endoscopy in Pediatric Environment in Brazzaville. Black African Medicine, 58, 277-280.

[12] Bobin, S., Culioli, F., Manach, Y. and Narcy. P. (1984) Caustic Ingestion in Children about 138 Observations. Acta Endoscopica, 14. https://doi.org/10.1007/BF02963103

[13] Mabiala-Babela, J.R., Pandzou, N. and Middle, G.M. (2010) The Accidental Pathology of the Infant in Pediatric Emergencies of the University Hospital of Brazzaville (Congo). Journal of Pediatrics and Childcare, 23, 185-190.

[14] Erreimi, N., Berrani, H., Meskini, T., Ettair, S. and Mouane, N. (2014) Ingestion of Caustic Product in Children about 13 Cases. Moroccan Journal of Childhood Diseases, 33, 8-10. 
[15] Rkain, M., El Kettani, S., Rhalem, N. and Benjalloum, B.S.D. (2011) Epidemiological Profile of Incidents and Accidental Acute Intoxications in Children. Medical EXpectancy, 18.

[16] Roida, S., Aitsab, L. and Sbihi, M. (2010) Ingestion of Caustic Product in Children. Journal of Pediatrics and Childcare, 23, 179-184. 